\title{
The translatability of culture-specific-terms in the Prophetic Hadiths: A case study of The Translation of the Meanings of Sahih Al-Bukhari
}

\section{Rana Abdel Fattah Salem ${ }^{(*)}$}

\section{Abstract}

The study demonstrates that culture-specific terms are still translatable in spite of the problems and challenges related to them. It mainly investigates the translation of culture-specific terms from Arabic into English in some Prophetic Hadiths in the book of The Translation of the Meanings of Al-Bukhari (1997) by Muhammed M. Khan. The study identifies the types of culture-specific terms in the Hadiths. Moreover, the study adopts Ghazala's model (2008) of translation procedures which he adapted from Newmark's model (1988) to explore the procedures utilized by the translator to convey the culturespecific terms. Furthermore, it examines its comprehensiveness and applicability to translate culture-specific terms in Hadiths. The findings show that the strategy of combining foreignization and domestication together, which is exemplified by the procedure of couplet or triplet, is the most adopted strategy according to the used procedures. This strategy is faithful to the SL and respects the TL and meets the expectations of the target readers.

\section{Keywords}

Translatability- culture- culture-specific terms- translation proceduresreligious translatio.

(*) This paper is part of an M.A. thesis entitled : The translatability of culture-specific-terms in the Prophetic Hadiths: A case study of The Translation of the Meanings of Sahih Al-Bukhari, Supervised by Prof. Bahaa el Deen M. Mazeed - Faculty of Al- Alsun, Sohag University \& Dr. Thanaa Alkady - Faculty of Arts, Sohag University. 


\section{Introduction}

Translation is an essential tool of communication between peoples of different cultures who speak different languages. This communication is necessary to convey the knowledge and progress and introduce the culture of foreign peoples to the target readers. Translation should not be dealt with only as a linguistic activity and the role of culture is ignored; however, it is a linguistic and cultural activity. Culture-specific terms are these terms related to different aspects of life which are unique to a group of people who have many common factors, subsequently, share the same culture. These terms may be recognized in some cultures and may be quite strange in other cultures; on this basis it is determined to what extent they are difficult to be translated. Cultural gap is the reason behind the problems that counter the translators when s/he translates these terms. The main problem is the problem of non-equivalence and sometimes even there is an equivalent it has different connotations. However, the lack of a direct equivalent for a term does not mean that this term is untranslatable, but it can be translated by using one of the suggested procedures. Different scholars suggested different models of the procedures of translation to overcome the problems of translation. This study adopts Ghazala's model (2008) which he adapted from Newmark's model (1988) to investigate the procedures utilized by the translator to overcome the problems. In addition, the study investigates under which strategies i.e. foreignization, domestication or the strategy of combining both of them are classified the procedures used by the translator to clarify the strategy that has the dominance in the translation.

Religious translation and specially the translation of sacred texts which are sensitive texts is one of the most difficult types of translation because it constitutes obstacles due to its sacredness and divine nature which is distinctive from other ordinary types of texts. Translation of Islamic texts is a must to convey the right teachings of Islam among people of different 
cultures who speak different languages and converted to Islam. Arab Muslim translator who is well-versed in Arabic and English may be more capable to translate Islamic sacred texts accurately than other translators because of his/her religious and cultural background. Moreover, the translator should consult exegesis books and specialized dictionaries to produce accurate faithful translation and should not depend on his/her personal knowledge or make his/her convictions intervene in the translated text.

\subsection{Research questions}

1. Are the specific-culture terms still translatable in spite of the problems and obstacles of translation?

2. What are the types of culture-specific terms in the Hadiths and what procedures are used by the translator to transfer these terms in the Hadiths?

3. Does the translator depend on the strategy of foreignization, domestication of the strategy or combining both of them in the translation?

4. To what extent Ghazal's Model of translation procedures is applicable and comprehensive to transfer the different categories of culture-specific terms in the Hadiths?

\section{Review of the literature}

2.1 The relationship between language, culture and translation

Each culture has its language that expresses it. The language of a specific social group, which is the means of communication among the members of this group, is affected by the culture shared by this group. Their culture reflects their attitude, religious beliefs, social customers, norms and their environmental conditions and ignoring this fact is a fatal mistake. Bassnett (2002) argues that" language, then, is the heart within the body of culture, and it is the interaction between the two that results in the continuation of life-energy" (p. 23). Furthermore, Wang (2014) states that "language and 
culture depends on each other ......in other words, language represents cultural reality" (p. 2423). The most accurate description of the relation between language and culture could be represented as "they operate as two parts of a whole rather than independently. Hence, "any study of language involves a study of culture too" (Pirnajmuddin \& Zamani, 2012, p. 71). So, no one of them is the predominant element but they are equally important during the process of translation. Language preserves and carries culture from one generation to another, and it is the vehicle for cultural communication and knowledge exchange among peoples. Culture constitutes and influences the language of a social group and their language mirrors the culture of this group. Thus, neither language nor culture can exist without the other; they are inseparable parts of a whole.

The relation between language and culture proves the role of culture in translation. As there is a solid relation between language and culture, it is certainly a relation between culture and translation. Translation is not a mere linguistic transmission between two languages but it is a cultural communication as well. This relation has introduced a new concept in the field of translation which is 'cultural turns'.

It is important here to see what is meant by culture. Sapir (1949) maintains that "culture is technically used by the ethnologist and culture historians to embody any socially inherited element in the life of man, material and spiritual" (p.79). Newmark (1988) simply and clearly defines it as "the way of life and its manifestations that are peculiar to a community that uses a particular language as its means of expression" (p.94). House (2002) sees culture as "the overall way of life of a community or society, i.e. all those traditional, explicit and implicit designs for living which acts as potential guides for the behavior of members of the culture" (p.93). A more recent definition for culture is stated by AlGhamdi (2016) which refers to culture as it "encompasses features that are not part of the biological system of human beings, but rather 
external features they adapted, as a reasonable species, to their natural and social environments" (p.169). So, how people think, believe, feel, speak and write is influenced by the culture they belong to, and it is especially for human beings and not for any other living beings.

Moreover, regarding the role of culture in translation Nida (1964) states that "the role of the translator is to facilitate the transfer of message, meaning and cultural elements from one language to another and create an equivalent response to the receivers" (p.13). In the same vein, Napier (2002) argues that translation is "the process by which concepts and meanings are translated from one language into another, by incorporating cultural norms and values; assumed knowledge about these values, and the search for linguistic and cultural equivalents" (p.28). According to Faiq (2004) "the conception of the intrinsic relationship between language and culture in translation studies has led to theories and arguments calling for the treatment of translation as a primarily cultural act"(p.2). Also, Hervey and Higgins (2004) maintain that the process of translation "involves not just two languages, but a transfer from one whole culture to another" (p.31). So, it can be said that communication which is the main purpose of translation involves language and culture, and any operation of translation is a lingual and cultural communication.

\subsection{Untranslatability Phenomenon in Translation Process}

Untranslatability is a phenomenon in the translation process that can occurs at different levels of a text. Shuttleworth and Cowie (1997) define translatability as "a term used - along with its opposite, untranslatability- to discuss the extent to which it is possible to translate either individual words and phrases or entire texts from one language to another "(p.179). Untranslatability at the word level refers to the non-existence of a direct equivalent for an SL item in the TL; the equivalent which does not convey only the denotative meaning of the SL 
item with all its linguistic features but also convey its cultural connotations(Kashgry, 2011). Besides, Zepetnek (1995) defines untranslatability as" a situation in which the linguistic elements of [ST] cannot be replaced or encoded adequately in structural, functional or semantic terms as a consequence of a lack of denotation and connotation in the language of [TT]" (AlGhamdi, 2016, p.37). Untranslatability arises because each language has its own vocabulary, its own phonology, its own grammar and its culture in which it functions

Regarding the notion of untranslatability, Newmark (1988) states that" everything without exception is translatable; the translator cannot afford the luxury of saying that something cannot be translated" (p.6). Nida (1975) has the same opinion "that anything can be said in one language can be said in another with reasonable accuracy". Also, he argues that "perfect communication is impossible; there are no exact correspondences between related words in different languages and all communication is one of degree" (as cited in Faisal, 2014.pp.339-340). Cui (2012) argues that "untranslatability is not absolute; we should understand the co-existence of translatability and untranslatability". Based on this, "we can use some methods to compensate in order to reduce the barrier in translation and promote language and culture communication" (Cui, 2012, p.826). In this respect, Hatim and Munday (2004) see that untranslatability is "a relative notion and it has to do with the extent to which, despite obvious differences in linguistic structure (grammar, vocabulary, etc.), meaning can still be adequately expressed across languages" (p.15). Furthermore, Barnstone (1993) claims that " in translation, the SL and TL text 'can never be equal', i.e. can never be identical, yet there will be translatability and information transfer 'with a remarkable degree of fidelity' which facilitates understanding"(AlGhamdi, 2016, p. 36). Aldahesh (2014) confirms that the translatability seems to be 
more reasonable than untranslatability as two approaches in translation. He states that

due to the expansion in the concept of translation, and the many strategies that a translator can resort to when confronted with a linguistic and/or cultural gap between two languages, the debate on translatability versus untranslatability has recently become unpopular and lost part of its validity (p.26).

He also points out that "this does not mean that perfect translation is attainable" (p. 26). The translation of a term may fail to convey all its linguistic features as the stylistic and rhetoric features or its cultural connotations, but translation at least can convey the meaning and communicate what the term means; even it is devoid of its aesthetic aspects. Accordingly, the aim of translation is transferring the message, meaning and idea of the ST to the TT not the words and structures that carry them and who claim untranslatability seek to perfection and complete correspondence which cannot be achieved in many cases because of the difference between languages. In this context, AlGhamdi (2016) mentions that Steiner (1998) advocates translatability and rejects untranslatability and he asserts that" although translation can never be perfect, it has always been a means of understanding (p.38). Human languages may have common features and universals among them but it is still each one has its particularity. Translator's proficiency plays an important role so what is apparently untranslatable for a translator, may be translated by another brilliant translator.

Catford (1965) distinguishes between two types of untranslatability: linguistic and cultural untranslatability. In linguistic untranslatability "the functionally relevant features include some which are in fact formal features of the language of the SL text. If the TL has no formally corresponding feature, the text, or the item, is (relatively) untranslatable" (p.94). 
For cultural untranslatability he argues that it happens "when a situational feature, functionally relevant for the SL text, is completely absent in the culture of which the TL is a part" (p.99). He considers this type as is less absolute than linguistic untranslatability. Snell-Hornby (1988) argues that" the translatability of a text depends on the extent to which the text is embedded on its own specific culture and also on how far apart, with regard to time and space, the ST and TL receivers are" (BraÇaj, 2104, p. 334).

The lack of a direct equivalent for an item does not mean that this item cannot be translated, but it can be translated by using one of the suggested procedures. For the sake of accurateness, it is better to call such cases as "difficulties in translation" not "untranslatability" because "untranslatability" means it cannot by translated any way while "difficulties in translation" means it cannot be translated using a direct equivalent but can be translated using a different compensatory procedure.

\subsection{Defining Culture-specific terms}

These terms are related to different aspects of life which are unique to a group of people who have many common factors, subsequently, share the same culture. These terms may be recognized in some cultures and may be quite strange in other cultures; on this basis it is determined to what extent they are difficult to be translated. Altahri (2013) states these terms include "words, terms, expression and concepts that are created for a particular culture and are only comprehensible to that culture" (p.78). Such terms cause several problems during the process of translation because every culture has its privacy which is represented in its vocabulary, concepts and terms that may be unique and exist in one culture but not in the others. However, the translator tries to maintain the same effect of the original text on the SL readers on the TRs a matter which in many cases is difficult or even impossible to be achieved. 
Newmark (1988) argues that "when there is a cultural focus, there is a translation problem due to the cultural 'gap' or 'distance' between the SL and TL"(p.94). Consequently, these items may not have equivalents in the TL because the facts, objects, phenomena, ideas...etc that these items denote are unknown in the TC i.e. not lexicalized in the TL (Baker, 2011) or have partial equivalents that do not convey the implications of the SL item. Newmark defines culture- specific items as items "tied to the way of life and its manifestations that are peculiar to a community that uses a particular language as its means of expression" (1988, p. 94). Also, Schwarz gives them a similar definition which is" concepts in any language that are unique to that language or to the culture associated with that language and create a cultural gap between speakers of different languages" (2003, p. 14). Culture -specific terms are the linguistic signifier of phenomena (signified) that are particular to a certain culture and distinguish it from another one. The translation aims to transfer these terms among cultures to introduce to a culture the specific features of another one in different aspects of life, such as the social and religious aspects, for example. The particularity of these terms that express specific phenomena leads to problems during translation. In the culturally loaded texts as religious texts, culture-specific terms play an essential role in understanding the meaning of the ST and conveying it to the TT. Wilss (1996) argues that "recognizing the meaning of culture-specific items is very important, as they are thorny in cross-cultural communication" (AlGhamdi, 2016, p.172).

The degree of the translatability of a text varies with extent to which it is embedded in its own culture and to the cultural distance between the source text and the target audience in terms of time and place (Snell-Hornby, 1988). Al-Azzam (2005) adds that "the more a culture is remote and deeply distant in history, the more difficult translation becomes"(p.117). This is the case when translating between 
Arabic and English because each one belong to different origin, so complete equivalent may be impossible in some cases. Arabic is a Semitic language while English is an IndoEuropean language. An example for clarification is the translation of an ancient Arabic text that was worded in a classical language to a contemporary target language like the modern English. In this case the temporal and spatial context in which the SL text is originally given is totally different from the temporal and spatial context of the TT.

Dweik and Suleiman (2013) point out that the disability to achieve the appropriate equivalence because of unfamiliarity with the source and target cultures and the incapacity to use the suitable technique are the problems that face the translators in translating culture-specific expressions. They add that the insufficient knowledge of the context of the source term as well as its connotative meaning may also problems encountered the translators.

Alwazna (2014) argues that adopting pure domestication or pure foreignization as a cultural strategy to translate culturespecific elements in a text would lead to violence or exoticism because the same text may include culture- specific elements besides other typical lexical. He sees that adopting a doublestrategy gathering the both strategies would be the best solution in such a case. He adds that Western translators resort to domestication in Arabic-English translation to produce a text that fit the TC.

Obeidat \& Abu-Melhim (2017) investigate the strategies that are used to translate a sample of 10 English-Arabic formula labels. The researchers classify the strategies used under the Venuti's two notions of foreignization and domestication. They do not follow a specific model of strategies to examine it but they focus on 8 strategies defining and explaining them according to different references by different scholars. According to them, there are four strategies exemplify foreignization which are: literal translation, 
transliteration, borrowing and transference. The other four used strategies are classified under domestication which are: transposition, omission, addition and adaptation. The comparative quantitative analysis they follow in the study proves the dominance of foreignization on domestication.

\subsection{Issues in religious translation}

Religious translation can be represented by an equilateral triangle which has three main angles, culture, religion and language. Culture and religion are major barriers in conveying a message from one language into another which is the aim of the process of translation. Religion has a great influence on the society; it constitutes a major part of its culture, consequently, affects its language. Prabhavananda \& Isherwood (1944) state that "part of the exceptional nature of holy texts lies in their function as behavior models for individuals, communities or whole cultures" (as cited in Alajlan, 2016, p.145). Each religion has its own particularity, concepts, values and rituals on which it is based. Therefore, losing the spirit of the original term is unavoidable matter in many cases. Translating sacred religious texts constitutes obstacles because of its sacredness and divine nature which is distinctive from other ordinary types of text. Besides, they constitute the base of the people's faith. Each religious text is related to a specific cultural context which plays a crucial role in its understanding.

The main problems of Islamic religious translation are nonequivalence and the close (partial) equivalent due to the linguistic and cultural differences or ideational hurdles. Nonequivalence means "the target language has no direct equivalent for a word which occurs in the source language" Baker (2011, p.18). In other words, it means the absence of the equivalent in the target language; equivalent that has the same referent and connotation of the SL term. Islamic religious term may have connotative meaning besides its denotative meaning 
and this obliges the translator to find the equivalent that conveys the both meanings to fulfill his task successfully. So the problem of the close equivalent means there is an equivalent for the source word but it does not convey the both meanings i.e. denotative and connotative meanings by this TL single word as it is in the SL. The rich implications included in the Islamic religious term may make the equivalent, if it is available in the target language, unable to convey the same implied meaning. The non-existence of a direct equivalent and avoiding the confusion of the partial equivalent may lead the translator to resort to one of the suggested strategies to deal with such terms.

Ghazala (2014) argues that translation is not limited only to find a direct equivalent, otherwise, the translation of the term "qbla" which is (prayer direction) is not a translation but a paraphrase. He also confirms that the concept of translation should be wider than this and the main purpose of translation should be the best understanding of the SL term in the TL either it is a translation or a paraphrase. Besides, he points out that the degree of understanding the Islamic term varies from one person to another depending on which degree the TR is close to or far from Islam (ibid). In this respect, Saeed (2006) confirms that conveying the meaning of religious texts from one language to another is no more than an approximation because of the divine nature of these texts. "The concept of ideal or perfect translation is illusory; the concept of translation equivalence can only be approximation" (Newmark, 1991, p.101). Moreover, the translator is needed to be knowledgeable of the Islam and read the exegesis of each term in an authorized source in Arabic so that s/he can understand its meaning and can translate it precisely.

Some researchers see that literal translation is the appropriate procedure to transfer the Islamic terms. For instance, Pirnajmuddin \& Zamani (2012) carried out a study on the procedures used in translating the terms related to practical 
laws of religion in five English translations of the holy Qur'an. The results show that literal translation is the most frequently and appropriate procedure from the seven procedures suggested by Ivir (1987). This because of "its faithfulness to the source language expressions and its transparency to the target language" (Pirnajmuddin \& Zamani, 2012, p. 80). Halimah (2017) points out that foreignization is the preferred orientation generally in translating Hadiths without referring to specific procedure. Besides, he asserts that Hadiths are divine texts given by a human which require a translator with specific characteristics to be able to translate them. Actually, literal translation (one of the procedure of foreignization) is not always faithful to the SL because the connotations of a term in the SL may differ from the connotations of the literal equivalent in the TL.

On the contrary; there are researchers who refuse literal translation as it may by a tool to destroy the intended meaning in some cases. For instance, Abdul-Raof (2004) argues that Arabic and English are different rooted culturally and linguistically languages and "literal translation of a text like Qur'an easily leads either to ambiguity, skewing of the source text intentionality, or inaccuracy in rendering the source message to the target language reader" (p.93). Consequently, what applies to the Qur'an applies also to the Hadith because both of them are sacred Islamic religious texts. Alshaje'a (2014) states that the translator "should always take the context into consideration by avoiding literal translation" (p.49). The context of religious texts cannot be understood without consulting authentic sources of exegesis. The translator cannot rely on his knowledge, even he is Muslim. Agung (2016) clarifies that literal translation may be preferred by some translators because it maintains all the hidden meanings behind the words, while free translation may loss some of the possible interpretations in the religious texts. Other translators stick to literal translation in translating religious texts to make the 
language of the religious texts sound unlike normal language of the ordinary people because it is the word of God. Agung refuses this orientation depending on what Nida (1997) states as it may be misleading and hinder the understanding of the target reader. Literal translation may be applied in certain situation and under certain conditions but also in several cases it may fail to convey the meaning and other appropriate strategies can be applied. Distortion the accurate intended meaning or changing an unfamiliar notion may lead to a great problem regarding interpreting religious teachings and duties or understanding forbidden and permissible matters.

Abdelaal\& Md Rashid (2015) demonstrate that the semantic loss in translating the holy Qur'an is caused mainly by "the cultural gap...... and the translator's relatively poor knowledge of the sciences of the holy Qur'an" (p.8). Advocating the same idea, Faisal (2014) argues that paraphrase is the most commonly used strategy in translating terms in the religious texts because it agrees with the norms of the target language.

\section{Theoretical framework}

\subsection{Equivalence as a Central Issue in Translation Studies}

Translation studies include a lot of important concepts that are vital to them, one of them is equivalence. Panou (2013) illustrates that equivalence became a central concept in translation studies in the 1960s and 1970s and it was meant by it the sameness between the ST and the TT. She adds that the kind and degree of sameness is the question which gave birth to different approaches of equivalence introduced by different scholars. Karimi(2000) simply defines equivalence in translation as decoding the ST by defining the meaning, message and intention of the original author then seeking to encode the same meaning, message and intention in the TL (Dewik \&Abu Helwah, 2014). Moreover, equivalence is defined simply as the concept that is "used by many writers to 
describe the nature and the extent of relationship which exist between SL and TL texts or smaller linguistic units" (Shuttleworth \& Cowie, 1997, p. 49). Kashgary (2011) argues that" equivalence is not a set of criteria which translations have to live up to, but is rather a group of features which characterizes the relationships linking the TT with its ST (p.50).

Although the concept of equivalence is a central issue in translation, it is a controversial concept in the field of translation studies regarding its definition and applicability. Wilss (1982) states that "there is hardly any other concept in translation theory which has produced as many contradictory statements as the concept of Translation Equivalence between SLT (source language text) and TLT (target language text)" (p.134). There is no universal approach to this concept since many scholars follow different approaches to deal with this concept.

Jakobson (2004) argues that "there is ordinarily no full equivalence between code - units" (p. 114). He sees that intrelingual translation involves replacing one message with an entire message not with separate words from one language to another one assuring that there is no full equivalence in meaning of words between two languages. The idea of full equivalence at all levels (form, content and the effect of the ST on the STs) between two different languages belonging to different linguistic systems and cultures is impossible. Equivalence exists but in certain degree not to the degree of completely matching between two texts in different languages.

Nida (1964/2004) introduces two different orientations which are "formal" and "dynamic" equivalence. Formal equivalence "focuses attention on the message itself, in both form and content" (p.129). Formal equivalence concentrates on the form and content of the ST, where they are reproduced as literally as possible in the TT. It is a ST oriented approach seeking accuracy for SL and correctness in the TL. On the 
other hand, dynamic equivalence focuses on "the principle of equivalent effect.... where the relationship between receptor and message should be substantially the same as that which existed between the original receptors and the message" (p. 129). Dynamic equivalence focuses on translating "thoughtfor-thought" rather than "word-for-word". It is a TT oriented approach seeking naturalness in the TT. To achieve naturalness in TT this may demand changes in grammar, lexical choice and adjustments of cultural terms. Nida points out that "correspondence in meaning must have priority over correspondence in style to achieve equivalent effect" (cited in Munday, 2012, p.68).

Catford (1965) introduces formal correspondence and textual equivalence. Formal correspondence is "any TL category (unit, class, structure, element of structure, etc.) which can be said to occupy, as nearly as possible, the same place in the economy of the TL as the given SL category occupies in the SL" (p. 27). He adds that "formal correspondence is nearly always approximate because every language defines its categories in terms of relations holding within the language itself". Textual equivalent, on the other hand, "is any TL form (text or portion of text) which is observed on a particular occasion to be the equivalent of a given SL form (text or portion of text)" (p. 27). Snell-Hornoby (1988) is one of the critics of Catford's linguistic theory of translation because Catford limits the translation process as a linguistic exercise without taking into account the cultural and situational aspects since translation involves different cultures not only different languages.

In Newmark's theory of equivalence (1981), he differentiates between two types of translation which are semantic translation and communicative translation. Communicative translation "attempts to produce on its readers an effect as close as possible to that obtained on the readers of the original" while semantic translation "attempts to render, as closely as the semantic and syntactic structures of the second 
language allow, the exact contextual meaning of the original" (Newmark, 1981, p.39). To make the distinguishing between the two types more clearly, it can be said that "semantic translation focuses on meaning whereas communicative translation focuses on effect" (Panou, 2013, p. 4). Newmark argues that if semantic translation corrupts the TT or does not achieve the equivalent effect then communicative translation should be preferred (Panou, 2013). In other words, the conflict between two types of translation would end in favor of communicative translation if semantic translation fails to producea text sounds normal.

Since equivalence is a central issue in translation, its absence is a problem encountered by translators. Kashgry (2011) argues that the concept of "non-equivalence" is as important and vital as the concept of "equivalence" in translation process. Her argument depends on Culler's statement (1976) which is "languages articulate or organize the world differently, and languages do not simply name existing categories, they articulate their own" (p.1). Because languages organize the world differently, the cultural and linguistic differences are inevitable matters which lead to exclude the idea of absolute equivalence and accept the idea of approximate equivalence. Nida(1964) refers to this fact emphasizing that the translators have to seek approximate equivalence not absolute equivalence because no two things are identical in two languages. Also, Hatim and Mason (1990) argue that the complete equivalence cannot be achieved somehow, supporting the idea of usage this term in a relative sense. They mean by relative equivalence the closest possible meaning to the ST meaning.

It is clear that the concept of equivalence is a controversial concept in translation studies and scholars define it from different perspectives. Accordingly, it does not have a fixed definition. Furthermore, the idea of absolute equivalence in terms of form, meaning, style and effect is not workable 
because languages organize the world differently; the idea of approximate equivalence is more reasonable.

\subsection{Domestication and Foreignization in Translation}

Domestication and foreignization are two strategies that are mainly concerned with the cultural aspects of the texts and represent two different orientations adopted by the translator during translation. They were introduced by the American translation theorist Venuti (1995). Venuti (1995/2004) defines domestication as "an ethnocentric reduction of the foreign text to target-language cultural values, bringing the author back home" and foreignizaton as "an ethnodeviant pressure on those values to register the linguistic and cultural difference of the foreign text, sending the reader abroad" (p.20). Domestication minimizes the strangeness of the original text by abandoning something of the otherness of the original language and culture which results in a fluent and transparent translation to the target readers; it observes the TL conventions. On the other hand, foreigniztion maximizes the strangeness of the original text by conserving something of the otherness of the original language and culture which results in a more strange translation for the target readers; it observes the SL conventions. Domestication is a target-text orientation while foreignization is a source-text orientation.

As any concepts in translation studies, foreignization and domestication have their supporters and critics due to the risks of each one. Foreignization maintains the norms of the SL and the SC, thus introduces a different culture and knowledge to the TRs. This helps the translation to achieve the cultural and knowledge exchange between peoples which is one of the main aims of translation. But at the same time it stands out the differences between the two languages and cultures that may expose the text to the risk of being abnormal and incomprehensible for the TRs. One the on the hand, Domestication helps the translator to overcome the linguistic 
and cultural differences which constitute the problems in translation. The target readers' understanding of the text is easier, as far as the translated text is close to their language and culture; a matter that helps to achieve the communication function of translation. The adoption of this method may be risky because it imposes the dominance of the TL and the TC on the original language and culture. Besides, it excludes the $\mathrm{SC}$ values and prevents the TRs from recognizing a different culture.

The nature of the text can be the tool on which the translators can rely to determine which strategy to adopt. Besides the nature of the text, the TRs and the purpose of the translation are also essential factors to determine which strategy would be more appropriate. Religious texts are different from the literary and technical texts because they are sensitive texts. Translating religious text is a case which needs the usage of the two strategies not only one of them. Sun (2011) indicates that" foreignization and domestication are indispensable and supplementary to each other and the idea that truly successful translation will depend on the unity of the two methods should be kept as a golden mean in every translator's mind" (p.163). In this context, Mansour (2014) conducted a study on the applicability of domestication and foreignization in translating culture-specific references of an English text into Arabic. The finding show that " it is hard to adhere to one strategy and follow it blindly, as our wish in translating such a piece is to inform, amuse and preserve our culture and norms" (p. 23). Obeidat \& Abu-Melhim (2017) illustrate that foreignization and domestication " could be used both within the same text that is to be translated despite the fact that they could vary in terms of adequacy" (p.64). Wang (2014) also concludes his study that the adopting of foreignization or domestication is not fixed as each one should complete and supply each one. He argues that the translator should mainly adopt foreignization because it is faithful to the original work, 
preserves the local flavor of the SC and introduces a different and new culture to the TRs. He adds that domestication plays the supplementary role and the translator should resort to it when foreignization is unable to communicate the intended meaning. To put it clearly, in the translation of a religious text the priority is to foreignization to convey the text faithfully and preserve it from the interventions. In a case that foreignization cannot express the intended meaning, destroys it or confuses the TRs; domestication plays a supplementary role. So, both of them are required to be adopted together within the same text.

foreignization and domestication are not procedures in translation, but they are two strategies under which fall different and variety procedures. They can be put on the two extremes of a scale on which the procedures are graded according to their proximity and remoteness from both strategies. The level of the target readers and to what extent $\mathrm{s} /$ he is near or far from the SL, the purpose of translation and the nature of the texts are all factors affect the choice of the translator of one strategy or both of them. When the translator adopts foreignization or domestication appropriately or even combines them (where it is required), he can satisfactory the TRs and achieve the intercultural communication successfully (Wang, 2014).

\section{Methodology}

\subsection{Data collection}

The data of this study was selected from the book of The Translation of the Meanings of Sahīh Al-Bukhāri (1997) by Muhammed Muhsien Khan. To achieve the aim of the study some Hadiths and their translations were selected from the book of The Translation of the Meanings of Sahih Al-Bukhari. These Hadiths contain culture-specific terms belonging to different categories of the categories of culture-specific terms. The Hadiths were selected depending on observation. 


\subsection{The model of analysis}

This study depends on Ghazala's model (2008) to analyze the procedures. This model contains 16 procedures: Cultural equivalent- cultural correspondence- naturalization- general sense- transcription- literal translation- translation couplettranslation triplet- classifier- neutralization- componential analysis- paraphrase- translation label- deletion- glossary/notes and footnotes. This is the model that is adopted in the study because it is a recent and comprehensive one, in addition to being an applicable model to all kinds of culture-specific terms.

\section{Data analysis and discussion}

The Arabic culture-specific term is identified in each Hadith and its translation. Then the procedure used from Ghazala's model (2008) to translate the term is clarified. In addition, the category to which these terms belong to is pointed out. After this, the procedure used is classified under foreignization or domestication.

\subsection{Analysis of the terms}

\section{Example (1) Hadith No. 336}

The term "تيمم" is a religious term related to Islam particularly so it is a culture-specific terms according to Newmark's classification (1988). The translation difficulty of this term is that the concept of this term does not exist completely in the TC, consequently, it is not lexicalized in the TL. Therefore, the translator adopts the procedure of transliteration. This procedure is the easiest and the most common procedure of translating the cultural terms. However, it is considered the least successful one because it may refer to the translator's inability. Nevertheless, in many cases this procedure may be the only solution in translation (especially in Islamic translation). Newmark (1988) argues that such a procedure should be followed by another one (translation couplet). This what the translator did exactly. He adopted 
transliteration followed by a point in a glossary at the end of the book which is" To put or strike lightly the hands over clean earth and then pass the palm of each on the hack of the other, blow off the dust and then pass them on the face. This is performed instead of ablution (Wudû') and Ghusl (in case of Janaba). (vol. 9 p. 430). By utilizing these two procedures, namely transliteration and glossary, the procedure of couple is used. Transliteration is a strategy of foreignization while glossary is a strategy of domestication (target-language oriented), so the translator combines both of them. It can be considered the appropriate solution to translate the religious terms, where the translator sacrifices neither the sacredness of the original term nor the TR's understanding.

\section{Example (2) Hadith No. 3205}

The term "عاد" is a name of a tribe so it is classified under the category of historical terms according to Newmark's classification (1988). It is transferred by transliteration and glossary to give detailed information about the term. 'A $d$ is "An ancient tribe that lived after Nah (Noah). It was prosperous, but disobedient to Allah, so Allah destroyed it with a violent destructive westerly wind (vol.9, p.401)". In this situation, the translator combines both foreignization (transliteration) and domestication (glossary) to convey the meaning in an accurate and appropriate way.

\section{Example (3) Hadith No. 3920}

The term "الحناء" /Henna/ is "a kind of plant used for dyeing hair etc" (vol.9, p.410). From the definition the term can be classified under the new subcategory of cosmetics and the subcategory flora which is classified under the category of ecology in Newmark'd classification. The term is transferred by the procedure of triplet (transliteration plus naturalization and glossary). The word Henna was borrowed from Arabic and naturalized to meet English spelling and pronunciation and 
became a part of English vocabulary, so there is no need to transliteration to create a state of strangeness and confusion to the TRs. Transliteration (Hinnā') is not the appropriate choice here, naturalization (Henna) is sufficient, more appropriate and understandable choice. Henna is a reddish-brown dye made from the powdered leaves of a tropical shrub, used to colour the hair and decorate the body (Oxford dictionary). Naturalization is a procedure of domestication.

\section{Example (4) Hadith No. 5401}

"خزير" is a name of a meal so it is classified under the subcategory of food which included in the category of material culture in Newmark's classification. It is transferred by transliteration / Khazīra/ and componential analysis in a form of a point in the glossary. It is "a special type of dish prepared from barley-flour, meat-soup, fat etc" (vol.9, p.415). In another words, the translator adopts the procedure of couplet which considered the appropriate selection in this case due to the cultural gap.

\section{Example (5) Hadith No. 3089}

" is a unit of weight in Arabic countries. It is classified under the subcategory of measurements. The subcategory of units of measurements is included only in Fernandez Guerra (2012) under the category of names of everyday objects. It is transferred by transliteration /Uqiya/ because it is specific for Arabs and has no equivalent. The transliteration is followed by a point in the glossary (vol.9, p.403) to give sufficient information. "5 'uāq = 22 Silver Riyals of Yemen or 206 Silver Dirham (i.e. 640 grams approx.) (See Sahih A1-Bukhfiri, Hadith No. 1447)". It is worth mentioning that the value of uqiya differs from one region to another.

\section{Example (6) Hadith No. 5975}

/W'd āl-banāt/ "وأد البنات" was a habit during the pre-Islamic period because it was shame to have daughters at that time, but 
it is prohibited in Islam. It is clearly classified under the category of habits. It is rendered by transposition and paraphrase to bury your daughters alive. Transposition is adopted by the translator to change the class of the word "وأد" from noun to verb "to bury". Paraphrase is suitable and successful to convey the meaning of the SL term. Actually, the procedure itself is correct but the explanation it gives is not accurate. The word "daughter" refers to females in different ages but only infants were involved in this awful crime. Accordingly, "to bury your female infants alive" is more accurate.

\section{Example (7) Hadith No. 7176}

"عريف" it was a rank in the past in the Arabic countries of a person who had headed a group of people. It is rendered by transliteration and a footnote (i.e. couplet procedure). It is classified under the subcategory of ranks which is included in the category of social terms in the classification of Fernandez Guerra (2012). This position was known in the Arabic culture, so it represents a cultural gap to be rendered to another culture. Thus, transliteration is required in addition to explanation which is in a form of a footnote. 'Urafä' is "the plural of 'Arif, the title of a person who is appointed to head a group of people to find out their problems and needs and inform his seniors about it. It is a rank below Amīr" (vol. 9, p.183).

\section{Example (8) Hadith No. 365}

Each of "تباء" and "تباء" are types of garments. To put it simply, they are classified under the subcategory of clothes under the category og material culture in Newmark's classification. All of them are transferred by the procedure couplet. /Izār/ and /Qabā'/ are transferred by transliteration and glossary while/ Tubbān/ is transferred by transliteration and a footnote. Izār is" a sheet worn below the waist to cover the 
lower-half of the body" (vol.9, p.413). Qabā' is" an outer garment with full length sleeves" (vol.9, p. 422). Tubbān is "shorts that covers the knees" (vol.1,p. 246). Such garments have special specifications that need to be clarified to the TRs so that the translator uses the glossary and the footnote.

\section{Example (9) Hadith No. 6209}

The fixed expression "ويحك/waihaka/ in Arabic is an invocation of Allah. It literally means May Allah be Merciful to you as it is clarified by the paraphrase. It is classified under the category of linguistic culture which is included in the classification of KU (2006). This expression has no equivalent in the TL, thus it is transferred by the usage of transliteration and paraphrase. The usage of paraphrase is accurate by which the SL is not violated and the TR is not confused. The paraphrase of this term is repeated in the glossary, so the glossary can be dispensed with because it is useless.

\section{Example (10)_Hadith No. 5379}

The term "قصعة" belongs to the category of tools which included in the category of names of everyday objects in Fernandez Guerea's classification (2012). It is translated by the procedure of general sense as "dish" and ignored the cultural charge of the SL term. Almaany dictionary defines "قصعة" as a big wooden or ceramic container used to serve food. "Dish" is a shallow, flat-bottomed container for cooking or serving food (Oxford dictionary). The term is not crucial to the meaning of the Hadith. So neither transliteration nor glossary is required so as not to create a case of ambiguity and strangeness for the TRs.

\section{Example (11) Hadith No. 523}

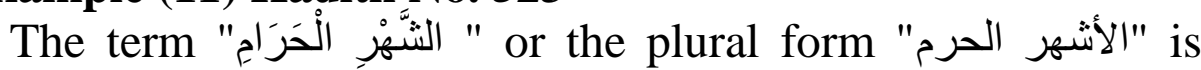
classified under the category of religious terms. They are four months (Rajab, Dhū al-Qa'dah, Dhu al-Hijjah and Muharram) 
during which Allah prohibits fighting. Fighting was also prohibited during these months in the Pre-Islamic time. The translator adopts the procedure of literal translation and translates it as sacred months. Oxford dictionary defines "sacred" as Connected with God or a god or dedicated to a religious purpose and so deserving. So, literal translation is acceptable but it would be clearer and more appropriate to add a short explanation between two brackets e.g. (the four months in Islamic calendar during which Allah prohibits fighting) or give detailed information in a footnote in the glossary.

\subsection{The procedures adopted by the translator}

The analysis of the translations of culture-specific terms in the Hadiths demonstrates that the translator relies on some procedures from Ghazal's model (2008) in translating the data. These procedures are: transliteration, literal translation, paraphrase, general sense, transposition, couplet and triplet. Foreignization and domestication are well-known strategies in translation suggested by Venuti (1995/2004) under which the previous procedure can be classified. A third strategy can be added to them which combines the two strategies together in one procedure. It is presented by the procedure of couplet and triplet. The analysis shows that the strategy of combining foreignization and domestication together is the highest used strategy compared to foreignization and domestication alone. The lowest used strategy is foreignization. This strategy is faithful to the SL and respects the TL. It is not necessary for the translator to apply only one strategy during the process of translation i.e. foreignization trying to bring the target reader to the source text or domestication trying to bring the text to the target reader. He has to be flexible and combine both of them if it is required according to the nature of the term itself. Elnaili (2014) argues that" both strategies complement each other......and cultural equivalence is better accomplished when

\section{0}


a translator domesticates the form and foreignizes the content in order to have a balanced" (p. vi).

Data analysis demonstrates that Ghazala's model is applicable to transfer culture-specific- terms in the Hadiths, and comprehensive to cover the procedures used in the data.

\subsection{Types the cultural categories in the data}

This section illustrates the types of the cultural categories in the Hadiths. These categories are: religious terms, historical terms, material culture, names of everyday objects, linguistic culture and social terms. These categories are included in different classifications. The classification of these categories in the study depends on the classification of different scholars and researchers which includes Newmark (1988), Fernandez Guerra's classification (2012), Oltra- Ripoll's (2005) and KU (2006) (cited in Fernandez Guerra, 2012, p.4). The new subcategory of cosmetics is a new subcategory suggested by the researcher which is included in none of the previous mentioned classifications and can be added to the category of material culture.

\subsection{Translatability of culture-specific terms}

Analysis and discussion demonstrate that culture-specific terms are still translatable even there are no direct equivalents. Surely, there are problems and difficulties regarding their translation, but they can be overcome by adopting the various procedures suggested by different scholars. The meaning of translation should not be limited to finding direct equivalents because it impossible in many cases. It worth mentioning that the more the term is rooted in a specific culture and has no traces in the target culture, the more it is difficult to be translated because of cultural gap. In addition, the difficulty increases when the ST is related to a specific time and place in the past which may contain terms that are no longer used currently in the SL; the translation from 
contemporary language is less difficult. Also, it increases when the distance between the SL and the TRs is long. Furthermore, the procedure used to translate any types of terms depends on the nature of the term itself, its importance in the text and the level of the readership. However, the translator has to be accurate when s/he translates any types of terms in Hadith because it is a sacred text and to be so accurate when s/he translates religious terms.

\section{Conclusion}

After analyzing the translations of some cultural terms belonging to different categories in differnt Hadiths in The Translation of the Meanings of Al-Bukhari by Muhammed M. Khan, there are some concluding marks which are shown in this section. Firstly, non-equivalence, partially-equivalent terms, translator's unfamiliarity with the SC and $\mathrm{TC}$ and translator's inability to select the appropriate procedures are the main problems of translating culture-specific terms. However, it does not mean that they cannot be translated to the TL and are subjected to untranslatability. Moreover, the meaning of translation should not be limited to finding a direct equivalent but it should be the best understanding of the term in the TL. Furthermore, the lack of a direct equivalent for a term does not mean that this term cannot be translated, but it can be translated by using one of the suggested procedures. To put it simply, culture-specific terms are translatable in spite of the problems, and the aim of translation is to communicate the meaning not the words and structures that carry them and who claim untranslatability seek to perfection and complete correspondence which cannot be achieved in many cases because of the difference between languages and the particularity of each culture. What can be achieved in the cases of cultural gap is approximation as much as possible not identification. Secondly, religious translation differs from technical and scientific translations which depend on specific 
terms and do not allow a lot of interventions or changings, and from literary translation which may allow some interventions or changes to achieve pleasure and entertainment. Religious sacred texts are sensitive texts that include terms which belong to particular religion and related to certain culture. The translator of such texts should be as accurate and faithful as possible. Moreover, the translator should consult exegesis books and specialized dictionaries to produce an accurate faithful translation. Thirdly, data analysis demonstrates the comprehensiveness and applicability of Ghazala's model (2008). Most the procedures used in the corpus are included in Ghazala's model. Furthermore, the strategy of combining foreignization and domestication together is the highest used strategy compared to foreignization and domestication alone; it is exemplified by the procedure of couplet and triplet. This strategy is faithful to the SL and respects the TL and meets the expectations of the target readers. 


\section{References}

2. Abdelaal, N\& Md Rashid, S. (2015). Semantic Loss in the Holy Qur'an Translation With Special Reference to Surah Al-WaqiAAa (Chapter of The Event Inevitable). SAGE, PP1-10

3. Abdul-Raof, H. (2004). The Qur'an: Limits of translatability. In S. Faiq (Ed.), Cultural encounters in translation from Arabic (pp.91-106). Clevedon: Multilingual Matters LTD.

4. Agung. I. (2016). Translation Procedures in Translating Religious Terms. LINGUISTIKA, 23 (45), pp. 197-206.

5. Alajlan, S. (2016). Strategies in translation of Arabic Da'wah texts: A case study of "Don't be sad". International Journal of Language and Linguistics, 3 (5), pp. 144-152.

6. Al-Azzam, S. (2005). Certain terms relating to Islamic observances : their meanings with reference to three translations of the Qur'an and a translation of Hadith. Unpublished Doctor of Philosophy thesis, Durham University, Durham, Britain.

7. Aldahesh. A. (2014). (Un)Translatability of the Qur'ān: A Theoretical Perspective. International Journal of Linguistics, 6(6), pp. 23- 45.

8. AlGhamdi, R. (2016).Translating Religious Terms and Culture in 'The Sealed Nectar': A model for quality assessment. Unpublished Doctor of Philosophy thesis. University of Leeds, Leeds, UK.

9. Alshaje'a, H. (2014). Issues in Translating Collocations of the Holy Qur'an. Language in India, 14:8, 49-65.

10.Altahri, A. (2013). Issues and Strategies of Subtitling Cultural References Harry Potter Movies in Arabic. Doctor of Philosophy thesis. University of Salford, Salford, UK.

11.Alwazna, R. (2014). The Cultural Aspect of Translation: The workability of Cultural translation Strategies in 
Translating Culture-Specific Texts. Life Science Journal, 11(11), 182-188.

12.Baker, M. (2011). In Other Words: a Course book on Translation. London: Routledge.

13.Bassnett, S. (2002). Translation Studies. (4 ${ }^{\text {th }}$ Edition). London and New York: Routledge.

14.BraÇaj, M. (2014). Reflection on English, culture and Translation and Culture as A challenge for Translation process. Journal of Educational and Social Research 4(4) pp.332-337.

15.Catford, J.C. (1965). A linguistic Theory of Translation: An Essay in Applied Linguistics. London: Oxford University Press.

16.Cui, J. (2012). Untranslatability and Methods of Compensation. Theory and Practice in Language studies, 2(4), 826-830.

17.Dewik, B. \& Abu Helwah, W. (2014). Translating Historical and Religious texts from Arabic into English: Problems and Solutions. Hebron University Research Journal, 9 (1), 285-303.

18.Dweik, B. \& Suleiman, M. (2013). Problems Encountered in Translating Cultural Expressions from Arabic into English. International Journal of English Linguistics, 3(5), pp. 47-60.

19.Elnaili, S.(2014). Domestication and Foreignization Strategies in Translating Sinbad of the Arabian Nights. Unpublished doctoral dissertation, Louisiana State University, Louisiana, US.

20.Faiq, S. (2004). The cultural Encounter in Translating from Arabic. In S. Faiq (Ed.), Cultural encounters in translation from Arabic (pp. 1-13). Clevedon: Multilingual Matters LTD.

21.Faisal, A. T. (2014). Explicitation : A Problem-Solving for Translating Arabic Religious Non-Equivalent Items Into English. Adab El-Frahedy, 19, 333-356.

\section{5}


22.Fernandez Guerra, A. (2012). Translating culture: problems, strategies and practical realities. A journal of literature, culture and literary translation, 1-27.

23.Ghazala, H. S. (2008). Translation as Problems and Solutions: A textbook for University students and Trainee Translators. Lebanon: Dar El- Ilm Lilmalayin.

24.Ghazala, H.S. (2014). Translation of Islamic Terminology: Problems and solutions. Retrieved from https://islamhouse.com/en/books/459965/.

25.Halimah, A. (2017). Translation of Prophetic Hadeeths: Divine Challenges. European Centre for Research Training and Development UK, 5(10), pp. 1-18.

26.Hatim, B \& Munday, J. (2004). Translation: An Advanced Resource Book. Routledge: London \& New York.

27.Hatim, B, Mason, I. (1990). Discourse and the Translator. London and New York: Longman.

28.Hervey, S. \& Higgins, I. (2004). Thinking French Translation - Acourse in Translation Method French to English. (2 ${ }^{\text {nd }}$ Edition). London: Routledge.

29.House, J. (2002). Universality versus culture specificity in translation. Cambridge: Cambridge University press.

30.Jakobson, R. (2004). On linguistic aspects of translation .In L. Venuti (Ed), The translation studies readers (pp. 113-118). London and New York: Routledge.

31.Kashgary, A. D. (2011). The paradox of translating the untranslatab Equivalence vs. non-equivalence in translating from Arabic into English. Journal of King Saud University - Languages and Translation, 23, 4757.

32.Khan, M. (1997). The Translation of the Meanings of Sahih Al-Bukhari. Saudi Arabia: Darussalam.

33.Mansour, H. M. (2014) Domestication and Foreignization in Translating Culture-Specific References of an English Text into Arabic. International 
Journal of English Language \& Translation Studies, 2(2), 23-36.

34.Napier, J. (2002). Sign Language interpreting: Linguistic coping strategies. Gloucestershire: Douglas McLean.

35.Newmark, P. (1881). Approaches to Translation. Oxford: Pergamon Press.

36.Newmark, P. (1988). A Textbook of Translation. Hertfordshire: Prentice Hall.

37.Newmark, P. (1991). About Translation.UK, USA, Canada\& Australia: Mulyilingual Matters Ltd.

38.Nida, E. (1964). Toward A Science of Translating. Leiden: E.J. Brill.

39.Nida, E. (2004).Principles of correspondence .In L. Venuti (Ed), The translation studies readers (pp. 126140). London and New York: Routledge.

40.Obeidat, E. \& Abu-Melhim, A. (2017). Foreignization and Domestication in Translating English-Arabic Baby Formula Labels. British Journal of Humanities and Social Sciences, 17 (2), 50-66.

41.Oltra-Ripoll, M.D. (2005). The translation of cultural references in the cinema. In A. Branchadell \& L, M. West (eds). Less Translated Languages (pp. 75-91). Amsterdam and Philadelphia : John Benjamins.

42.Panou, D. (2013). Equivalence in Translation Theories: A Critical Evaluation. Theory and Practice on Language Studies, 3 (1), 1-6.

43.Pirnajmuddin,H. \& Zamani,B. (2012). A study of the translations of terms related to practical laws of religion (furū al-dīn): Raising students' awareness of culturebound items. Applied Research in EnglOish, 1(2), 71-82.

44.Saeed, J. (2006). Interpreting the Qur'ān: Towards a Contemporary Approach. London and New York: Routledge.

45.Sapir, E. (1949). Culture, Language and Personality. California: University of California. 
46.Schwarz, B. (2003). Translation in a confined space. Translation Journal, 7(1), 354-369.

47.Shuttleworth, M. \& Cowie, M (1997). Dictionary of translation studies. Uk: St. Jerome publishing.

48.Sun, H. (2011). On Cultural Differences and Translation Methods. Journal of Language Teaching and Research, 2 (1), 160- 163.

49. Venuti, L.(2004). The translator's invisibility: A history of translation. New York: Routledge.

50.Wang, F. (2014). An Approach to Domestication and Foreignization from the Angle of Cultural Factors Translation. Theory and Practice in Language Studies, 4(11), 2423-2427.

51.Wilss, W. (1982). The Science of Translation; problems and Methods. Tubingen: Gunter Narr Verlag. 